a certain number are every year discharged well. The "Treatment of Fractures of the Thigh" is the subject of a short article by Mr. Cisoper Forster.

Dr. Goodhart follows with a really useful contribution to our knowledge of the symptomatology of meningeal bromorrhage, founded on the well-kept case-books and postmortem records of the hospital, and the Transactions of the Pathological Society. Among the "Causes of Preventable Blindness," which Mr. Higgens discusses are granular ophthalmia, purulent ophthalmia, and undetected glaucoma. In each disease early and efficient treatment is strongly advocated, and the results of neglect are illustrated by examples. "The Use and Abuse of Sedatives," is discussed by Dr. Stokoe, of Croydon, who believes he can cut short pneumonia by aconite, and would treat it by opium, milk, and alcohol, other food being withheld. Mr. GoldingBird contributes a paper "On Statistics of the Amputations at Guy's Hospital during fifteen years," and this is followed by a very lengthy report of the labour-cases attended in connexion with the charity during twelve years. It has been compiled by Dr. Galabin with great care, and both statistics and details are full of interest.

The treatment of ulcers by the local application of a weak continuous electrical current has been extensively tried by Mr. Golding-Bird, who has found that as good a result is obtained as with any other gently stimulating application and that this means will sometimes succed when ordinary methods of obtaining cicatrisation fail. The remaining papers are some thoughtful "Remarks on the Paroxysmal Neuroses," by Dr. Hilton Fagge, who discusses the opinions held concerning them by some late writers; and an article by Dr. Pavy "On the Recognition of Sugar in Healthy Urine." The process which was lately shown at one of the societies is here fully described.

On Rest and Pain. A Course of Lectures delivered at the $R$ yal Coll $r$ ge of Surgeons of England in the years 1860, 1861, and 1862, by JoHn Hicton, F.R.S., F.R C.S., Surgeon Extraordinary to Her Majesty the Queen, Consulting Surgeon to Guy's Hospital, \&c. Fdited by W.H. A. J ACoBson, F.R.C.S. Second Edition. London : George Bell and Sons.

Wh encounter these lectures, cast in a new and improved form, with all the gratification that we should feel in meeting an old friend who had years gone by rendered us an essential service. We can recall the pleasure we had in reading these lectures goon after their delivery at the Royal College of Surgeons. They are rich in clinical facts, graphic in the description of cases, full of practical observations and valuable expedients-tbe results of a long and thoughtful experience. The subject was indeed worthy of being treated in that philosophical and scientific spirit in which it was considered; and we know of no more interesting, valuable, or suggestive book in surgical science than this volume of Mr. Hilton's lectures on Rest and Pain.

The School Manual of Geology. By J. BeETe Jukes, M.A., F.R.S., late Director of the Geological Survey of Ireland, \&c. Edited by AlFRed J. Jukms-BRowne, B.A., F.G.S., of the Geological Survey. Third Edition. Edinburgh : Adam and Charles Black. 1876.

WE remember being much pleased with the first edition of this very excellent little manual, and the present edition-the third-by Mr. Jukes-Browne, a nephew of the lamented author, has evidently been edited with great care and discrimination. Much new matter has been added or substituted for the old, which has, moreover, undergone considerable revision. The arrangement and style are alike good, and altogether we regard it as well adapted for schools and for persons who are desirous of gaining, at any rate, something like an intelligent idea of the subject.
Lessons in Electricity at the Royal Institution, 1875-6. BF JoHN 'I'YNDALL, D C.L., LL D., F.R.S. London: Longmang, Greeu, and Co. 1876.

THese form, with some amplification, the substance of a Christmas course of lectures given by Prof. Tyndall to a juvenile audience. They are what such teacbing requires to be-simple in language, well-arranged, and progressive, each and every step being either demonstrated or illustrated by experiments that are within the reach of anyone's performing for himself.

\section{CHLORAL POISONING; RECOVERY BY MEANS OF ELECTRICITY.}

To the Editor of The I.ANCET.

SIR,-I beg to for ward you a brief outline of the following instructive case.

F. D-, elderly married man, of intemperate habits, took, at 10 P.M, 13 th June, 1876, one and a half ounces of Hunter's solution of chloral, equal, I believe, to four drachms of chloral hydrate. I was sent for by his medical attendant, Dr. Hammond, at 1 A.M., 14th June. Patient's symptoms were then as follows:-Breathing, though occasionally stertorous, appeared every moment about to cease; pulse barely perceptible; heart-sounds almost inaudible; ejeballs immovable, pupils thoroughly insensible to light, and strongly contracted. The head, face, and hands wore cold and bluish; feet warm; eyelids closed; tongue swollen; if allowed to fall back patient became asphyxiated.

Treatment.-Double thread was passed through the raphe of the tongue, and secured well out of the mouth. Artificial respiration was maintained for several hours. The electric current of a magneto-electric machine was passed through the chest-walls and cranium. Finally the poles of a machine were secured to the hands, and currents passed with little intermission for upwards of eleven hours ! Brandy and beef-tea were administered per rectum. Whon consciousness returned patient was well smacked over the body, and kept awake during the greater part of the day. Brandy, coffee, and beef-tea, and effervescing drinks were now given by the mouth. He was then left in charge of lay attendants. He slept well the following nights, and made a good recovery.

Remarks.-Almost immediately after taking the solution the patient vomited a small quantity of fluid, which was not saved for our inspection. He was in the habit of taking this in teaspoonful doses in order to procure sleep, and as a substitute when he could not obtain drink. For seven hours the electric current failed to stimulate muscular contraction. At the end of that time the flexors of the forearms and fingers contracted under the stimulus, and shortly the external intercostals and levatores costarum were influenced, as shown by the deepened inspiration when an electric current was passed. Stertor came on whenever the current was omitted. The face now flushed, and the corrugator supercilii muscles were slightly affected. The coldness gradually disappeared, and a genial warmth overspread the body. Presently the eyelids were partially raised, the body was drawn up, the head thrown back, and the mouth shaped as if to ejaculate "Oh!" It was not, however, until eleven hours bad elapsed that the patient would call out when an eztra dose was applied. Soon he grumbled audibly. At this stage we substituted smacking, shoutings, \&c., for the electricity. If let alone, the patient immediately relapsed. It was found that the pupils dilated during the passage of the current. During the application of the magneto-electric machine, severe rigidity of the upper exlremities came on. Much soreness was complained of for several days following recovery. During the treatment, three machines were in use, one having three magnets, the others two and one respectively.

Unfortunately, no ther:nometer was at hand, so that at no stage of the case was the temperature taken.

I am, Sir, your obedient servant,

Timaru, Canterbury, N.Z. Geo. W. Cole, L.R.C.P.Ed., \&c. 